Université „Dunărea de Jos” de Galați, Roumanie

\title{
L'IDENTITE CULTURELLE ROUMAINE - PARTIE INTEGRANTE DE LA CULTURE EUROPEENNE AU XIXÈME SIÈCLE
}

Au début du XIXème siècle, l'identité culturelle roumaine se liait étroitement aux événements sociopolitiques de l'époque. La société «a changé » selon les modèles européens, ce qui a contribué à la formation de l'esprit identitaire et de la conscience nationale.

Dans le mélange d'influences nombreuses (venues de la France, l'Autriche, l'Italie, la Russie, l'Angleterre) le sentiment de l'identité se confondait avec celui de l'appartenance à l'espace où le peuple roumain même s'est formé. C'est un phénomène qui présente encore grand intérêt dans le contexte où les événements historiques ont laissé des traces dans les mentalités des gens.

La notion de conscience identitaire a directement agi sur les liaisons étroites entre les provinces roumaines. Selon les sources historiques, surtout celles venues de la part des chroniqueurs, la conscience identitaire roumaine s'est montrée plus soutenue en Transylvanie par rapport aux autres régions roumaines. D'ailleurs, les conditions historiques de la formation des territoires roumains extra-carpatiques (La Moldavie et La Valachie), ainsi que les liens avec la Transylvanie - ce sont des facteurs qui ont soutenu le sentiment d'appartenance des Roumains au même pivot identitaire. La langue commune parlée dans les provinces roumaines et, surtout, la croyance dans la vision d'un État uni ont renforcé l'idée de conscience identitaire, à laquelle se sont rajoutées les motivations historiques. Les activités concrètes qui ont visé l'espace roumain se sont manifestées dans le sens de la reconnaissance de l'existence de la nation roumaine en tant que partie constituante de la structure sociale moderne et, par-dessus tout, dans le sens de l'intention de reconnaître l'État roumain comme un tout unitaire. De plus, le droit du peuple roumain était celui de conserver et de sauvegarder la nationalité roumaine, ce droit-là étant incontestable. D'ailleurs, l'Union de 1859 et toutes les réformes novatrices ont mené à la constitution de l'État-nation. Sur cette toile de fond, les événements historiques ont indubitablement marqué le sentiment de l'identité nationale, qui vivifiait toutes les consciences de l'époque. 
Les écrivains roumains ont joué un rôle décisif dans la diffusion et la consolidation de l'idéal d'unité nationale. Ils se sont activement impliqués dans le bon déroulement dynamique des événements politiques par l'intermédiaire de leurs œuvres littéraires qui contenaient des messages patriotiques, avec des sens nationaux et sociaux, transformés, peu à peu, en échos glorieux des événements de l'époque. À cette époque-là, les écrivains ont accordé une importance particulière à la définition des concepts tels que "la patrie”, "la nation roumaine", "l'identité nationale", "l'État unitaire", ayant pour base assise les trois principes du modèle français : liberté, égalité et fraternité entre les individus.

Le début du XIXème siècle a été marqué, sur le plan politique, par la révolution de 1821, exemple pour une autre révolution, de 1848, véritable clé de voûte dans l'histoire de la consistance identitaire. Les événements politiques et l'enthousiasme révolutionnaire ont été des facteurs qui ont fait "germer" le sentiment identitaire national, proclamé dès lors. La culture, manifestée par le biais de la philosophie livresque, par le respect des valeurs nationales, ainsi que par les influences du monde occidental, a renforcé l'idée de nation roumaine moderne.

$\mathrm{Au}$ XIXème siècle, les provinces roumaines se confrontaient avec de nouveaux défis dans le contexte des influences politiques et culturels de l'Europe. Les conditions politiques et sociales influençaient les rapports culturels que les Roumains essayaient d'établir avec les pays de l'Europe occidentale. Les Roumains s'intéressaient à s'aligner aux autres pays, mais la culture roumaine était dominée par deux tendances complémentaires : l'exigence d'assimiler les idées et les modèles culturels occidentaux et le besoin des lettrés de créer des œuvres qui glorifiaient les caractéristiques de ce qui était spécifique roumain. Les gens voulaient, à tout prix, avoir une culture performante au niveau européen. L'enthousiasme culturel s'est manifesté comme un désir frénétique de créer, ce qui a mené à la synchronisation de la vie intellectuelle roumaine avec les grandes tendances culturelles occidentales, afin de faire bouger vers la modernité toute la société et la spiritualité roumaine.

Le désir des écrivains roumains d'avoir une culture représentative a encouragé leur confiance dans les valeurs nationales. L'espace culturel roumain a dû surmonter une crise «aigue » de la conscience européenne, étant soumis à des renouvellements qui ont préparé la transition vers une nouvelle époque, moderne.

Les structures sociales, économiques, mais surtout celles spirituelles se sont modifiées, en imposant de nouvelles règles et orientations. Dans les provinces roumaines, les réalités politiques et sociales ont abouti à 
l'institutionnalisation de la vie culturelle et à la genèse d'une structure culturelle moderne. La vie intellectuelle et les mécanismes pédagogiques se sont adaptés à de nouveaux paradigmes. L'enseignement, la presse et le théâtre visaient un processus d'institutionnalisation et de modernisation. La littérature roumaine s'est enrichie par les œuvres de Mihail Kogălniceanu, Alecu Russo, Nicolae Bălcescu, Gheorghe Asachi, Ion Heliade-Rădulescu, et la culture roumaine a été témoin de la naissance d'une nouvelle génération d'historiens, linguistes, écrivains qui ont fait que l'enseignement se développe. Peu à peu, la société roumaine s'est montrée ouverte à toute influence européenne, en faisant tomber "le dernier bastion" des influences barbares, orientales, fait soutenu dans les œuvres littéraires de la génération d'écrivains de 1848. Cette littérature-là a été considérée comme "prémoderne”, pas seulement du point de vue chronologique, mais idéologique aussi.

La tradition culturelle des provinces roumaines n'était pas riche, mais ses sources étaient attestées par des documents historiques. La question qui se posait se liait à l'idée de se vanter aux autres d'avoir une tradition culturelle au début du XIXème siècle.

Les idées du siècle des Lumières se faisaient connaître dans les provinces roumaines dès la fin du XVIIIème siècle. Les progrès de l'esprit scientifique, de plus en plus ressentis dans l'Europe entière, ont été nombreux dans les Principautés roumains aussi. Dans cet état des choses, un développement progressif de l'enseignement a été favorisé dans le cadre de l'éducation en vue d'une culture générale. Tout cela et d'autres nombreuses manifestations reflètent un processus de mise au point du sentiment de l'identité nationale.

Dans la première moitié du XIXème siècle, l'enseignement venait de se trouver sous l'égide de l'État et s'organisait de manière méthodique. L'esprit national gagnait du terrain et l'on a commencé à conclure des collaborations avec des institutions culturelles occidentales de prestige. Les écoles ont été un facteur déterminant pour l'instruction des gens et l'enseignement roumain a connu, tout comme dans les autres pays de l'Europe, des transformations particulières, car on visait la formation des gens qui soient capables de comprendre la vie et de la maîtriser. Pour cela, on a fait inscrire à l'école tous les enfants, sans aucune discrimination.

Un moment important dans l'histoire de l'émancipation des Roumains a été représenté par la fondation, après l'Union de 1859, de deux universités de prestige: L'Université d'Iaşi (en 1860) et celle de Bucarest (en 1864), ce qui a permis que les jeunes gens fassent leurs études dans leur pays. En 1862 l'on a créé le Ministère de l'Éducation Nationale (ou le 
Ministère des Cultes et de L'Instruction Publique), tandis que la première loi moderne de l'enseignement, La Loi de L'Instruction publique, a été promue en 1864, par le prince Al. I. Cuza, qui plaidait pour un système éducatif unique dans toutes les provinces roumaines.

L'espace culturel européen moderne a fait possible le contact des écrivains Roumains avec les nouveautés étrangères, contact qui s'est produit grâce aux érudits Grecs, qui ont traduit en leur langue des écrits classiques, préromantiques et romantiques, grâce aux traductions littéraires nombreuses et aux lectures des textes en langues sources, surtout en français. La traduction des textes en roumain est devenue le moyen le plus usé d'enrichissement du vocabulaire.

Quant aux liens avec les autres, G. Ibrăileanu considérait les relations culturelles entre les Pays Roumains et les pays étrangers comme un processus de renouvellement de l'esprit identitaire; il notait que

„le progrès de l'esprit roumain s'est fait simultanément avec l'influence occidentale, $[\ldots]$ ce qui justifie nos affirmations sur les influences salutaires de l'Occident, en même temps que sur les chroniqueurs Costinești et les autres qui s'avèrent être - historiquement et philosophiquement - les prédécesseurs de la génération de 1848. Ce sont les affirmations d'un homme de la génération de 1848." [1] [notre trad.]

À son tour, Alecu Russo soutenait l'influence salutaire du monde occidental en affirmant que les relations des Roumains avec le monde occidental s'étaient établies pendant le XVIIIème siècle, lorsque le clergé de Moldavie se réjouissait

„de préceptes et de dévotion. [...] À partir de l'époque des chroniqueurs Costineşti, qui avaient été éduqués en Pologne, et jusqu'à présent, toutes les voies menaient vers l'Occident, où nos enfants faisaient leurs études. [...]" [2] [notre trad.]

Comme l'on a déjà précisé, pour G. Ibrăileanu, le noyau culturel roumain se trouverait en Moldavie :

„L'histoire de la culture moldave du XIXème siècle est, par-dessus tout, l'histoire de cet esprit critique-là [...]. Il cherchait même à identifier les étapes dans l'analyse de l'apparition des modèles étrangers : c'est la même chose, l'histoire des luttes contre les fausses tendances, celles simplettes, de Valachie et Transylvanie..." [3] [notre trad.]

L'idée est continuée par l'auteur qui donne les noms des écrivains moldaves qui se sont remarqués à ce temps-là: 
"G. Asaki est contemporain avec deux époques de la littérature roumaine du XIXème siècle : la première, l'époque Conachi, pour ainsi dire, et la seconde, l'époque Alecsandri. Toutes les deux se trouvent sous des influences étrangères et en dépendent. La première, celle de Conachi, survit grâce aux influences de la littérature française classique décadente et de celle néogrecque, la dernière s'associant à la première : c'est l'âge de la sentimentalité faussement affectée, des abstractions personnifiées, des mythes, des sujets sans correspondance avec la vie courante, de l'inspiration insipide du passé antique. La seconde période a été crayonnée par les influences de la littérature romantique française - Hugo, Lamartine - qui était neuve à cette époque-là : sentimentalisme outré, couleur chatoyante, passé national, donc, médiéval." [4] [notre trad.]

E. Lovinescu considérait le principe du synchronisme avec la vie moderne comme la base assise de la civilisation roumaine :

„Il y a un esprit du siècle, appelé Tacitus saeculum, c'est-à-dire une totalité d'exigences matérielles et morales qui configurent les vies des peuples européens pendant une telle époque... L'esprit du temps n'est pas, en effet, un concept abstrait, mais au contraire, il dérive du degré de l'évolution intellectuelle tout comme de la situation économique de l'époque." [5] [notre trad.]

Paul Cornea proposait, à son tour, une analyse détaillée du phénomène en question, en écrivant que

„les peuples habitant les Balkans et le nord du Danube ont été également soumis à la domination ottomane, qui les a mis à écart des grands courants de la civilisation européenne pendant quelques siècles et les a fait ralentir le rythme du développement économique. Ceux-ci ont été, de même, privés de la possibilité de s'affirmer en tant qu'identités nationales et obligés à accepter, pour une période incertaine, une langue étrangère comme outil de la culture supérieure (le grec pour les Bulgares, les Serbes et les Roumains et le hongrois pour les Croates) [...]."

En outre, Paul Cornea notait :

"Quelle que soit l'intensité du processus d'appropriation culturelle (par exemple, pendant la période de la renaissance nationale), les traits communs à la zone n'estompent jamais les particularités de chaque peuple; par contre, celles-ci sont décisives, car elles distinguent les cultures, en leur conférant valeur, expressivité et sens." [6] [notre trad.]

Dans le contexte d'une crise identitaire des Roumains, au XIXème siècle, il y avait, pourtant, des événements socioculturels et politiques qui ont eu un impact majeur sur les mentalités des gens. En Transylvanie, les formes d'expression politique en rapport avec les réalités sociales et la participation aux « luttes » révolutionnaires et aux troubles populaires de 
l'Empire Austro-hongrois ont été des facteurs perturbateurs du rythme de la vie, car l'horizon de connaissance et le sentiment identitaire sont devenus plus dominants grâce aux liaisons directes avec les Roumains qui habitaient au-delà des Carpates. Le progrès de l'éducation et de la culture générale a contribué à la consolidation et à l'expression de l'esprit identitaire par l'orientation vers l'Occident et par «les arguments » historiques en tant que fondements d'une nation moderne. Par conséquent, le patrimoine culturel et identitaire roumain s'est enrichi grâce aux autres cultures, ainsi qu'aux éléments innovants qui se sont greffés sur le cadre autochtone déjà fondé.

\section{NOTES:}

[1] Garabet Ibrăileanu, Spiritul Critic în Cultura Românească [L'Esprit Critique dans la Culture Roumaine], Iaşi, Editura Tipo Moldova, 2009, p.38 [,...progresul românismului e concomitent cu influența apuseană, [...] ceea ce este o justificare a celor spuse de noi, că influențele salutare au venit din Apus şi că Costineștii şi ceilalți sunt - istoriceşte şi filozofește - premergătorii generației de la 1848. O spune, cum se vede un patruzecioptist."]

[2] Alecu Russo, Piatra-Teiului, Scrieri alese, Cugetări [Piatra-teiului. Écrits choisis. Pensées], Editura pentru Literatură, Bucureşti, 1967, p. 133 [„...de nume de învățătură şi de evlavie. [...] De la Costinești, crescuți în Țeara Leşească şi pînă la noi, tot drumurile Apusului sunt bătute de pruncii români."]

[3] Ibrăileanu Garabet, oeuvre citée, p. 42 [„Istoria culturii moldoveneşti din veacul al XIX-lea e, mai ales, istoria acelui spirit critic aplicat la introducerea culturii străine, adică la procesul de regenerare a spiritului românesc. El încerca, chiar o trasare de trepte în analiza pătrunderii modelelor străine: E, ceea ce e acelaşi lucru, istoria luptelor împotriva tendințelor false, necumpătate, din Muntenia şi Transilvania..."]

[4] Idem [„,G. Asaki, e contemporan cu două faze ale literaturii române din veacul al XIX-lea: cu prima fază a acestei literaturi, s-o numim faza Conachi şi cu o a doua, s-o numim faza Alecsandri. Ambele faze sunt condiționate de influențe străine şi se definesc prin aceste influențe. Prima fază, a lui Conachi, e datorită influenței literaturii clasice decadente franceze şi influenței literaturii neogreceşti, care seamănă cu prima: e vremea sentimentalității fals-exagerate, a abstracțiunilor personificate, a mitologismului, a subiectelor fără legătură cu viața contemporană, a inspirației searbede din trecutul antic etc. A doua fază e datorită influenței literaturii romantice franceze - Hugo, Lamartine - nouă pe atunci: sentimentalism puternic, culoare vie, dezgroparea trecutului național, deci, medieval etc."]

[5] Eugen Lovinescu, Istoria civilizației române moderne [L'Histoire de la civilisation roumaine moderne], vol. III, Editura Minerva, Bucureşti, 1992, p. 31 [„Există, scria Lovinescu, un spirit al veacului, numit Tacitus saeculum, adică o totalitate de 
condiții materiale şi morale configurătoare ale vieții popoarelor europene într-o epocă dată... Spiritul timpului nu e, de altfel, un concept abstract, ci se desprinde, dimpotrivă, din gradul de evoluție intelectuală ca şi din situația economică a epocii... Imprimând caracterul general şi organic al instituțiilor din diferite epoci, spiritul timpului e, aşadar, firul conducător al istoriei în controversele faptelor..."]

[6] Paul Cornea, Regula jocului. Versantul colectiv al literaturii [ La règle du jeu. Le versant collectif de la littérature], Editura Eminescu, Bucureşti, 1980, p. 202 [,...popoarele din Balcani şi de la nordul Dunării au fost deopotrivă supuse dominației otomane, care le-a izolat câteva secole de marile curente ale civilizației europene şi le-a încetinit ritmul dezvoltării economice. Acestea au fost deopotrivă împiedicate să se afirme ca personalitate națională şi silite să accepte o perioadă mai lungă sau mai scurtă o limbă străină drept instrument al culturii superioare (greaca pentru bulgari, sârbi şi români, maghiara pentru croați)" [...], [,...oricât de mare ar fi în anumite momente privilegiate (de exemplu, în perioada renaşterilor naționale), intensitatea procesului de apropiere, trăsăturile comune zonei nu estompează niciodată particularitățile proprii fiecărui popor; or, tocmai acestea sunt decisive căci ele individualizează culturile, dându-le valoare, expresivitate şi sens."]

\title{
RÉFÉRENCES BIBLIOGRAPHIQUES :
}

Cornea, Paul, Regula jocului. Versantul colectiv al literaturii [La règle du jeu. Le versant collectif de la littérature], Editura Eminescu, Bucureşti, 1980.

Ibrăileanu, Garabet, Spiritul Critic în Cultura Românească [L'Esprit Critique dans la Culture Roumaine], Editura Tipo Moldova, Iaşi, 2009.

Lovinescu, Eugen, Istoria civilizației române moderne [L'Histoire de la civilisation roumaine], vol. III, Ed. Minerva, Bucureşti, 1992.

Russo, Alecu, Piatra-Teiului, Scrieri alese, Cugetări [Piatra-teiului. Écrits choisis. Pensées], Editura pentru Literatură, Bucureşti, 1967.

\section{Romanian Cultural Identity - a Part of European Culture in the 19 $9^{\text {th }}$ Century}

\begin{abstract}
For integrate into the European cultures, the Romanian culture received, in the $19^{\text {th }}$ century many influences from all over the world. The various models of the arts and writings have contributed to a modern and new atmosphere and have been good examples to follow. The new creative atmosphere, specific to the European "horizons", was really favourable to the rise of the dynamic temperament of the Romanians, who understood that modernity had to prevail to create new socio-aesthetic awareness. On the cultural "battlefield" was disputing "the struggle" between tradition and modernity in all areas (social, literary, political). In our study, we propose some opinions of Romanian writers-critics
\end{abstract}


concerning the defence of Romanian cultural identity, as an integral part of European culture, especially in terms of the development of the creative spirit in mentalities and consciences of that time.

Keywords: Romanian cultural identity, European culture(s), influence, school education. 